\title{
OPTIMAL TURN-ON AND TURN-OFF ANGLES FOR TORQUE RIPPLE MINIMIZATION OF SWITCHED RELUCTANCE MOTOR
}

\author{
P. Srinivas \\ Assistant Professor, Department of Electrical Engineering, University College of Engineering, Osmania University, \\ Telangana, India
}

\begin{abstract}
Due to double saliency nature and non-linear magnetic characteristics the torque ripple is high in Switched Reluctance Motor. The torque ripple depends on the operating speed, current and turn off and turn-on angles of the converter. The performance of the motor is analyzed for Hysteresis Current Control with Fan type load with respect to torque ripple. The SRM with Hysteresis Current Control is analyzed for different combinations of turn-off and turn-on at a fixed reference speed to find out a pair of turn-on and turn-off angles at which torque ripple is minimum.
\end{abstract}

Key Words: Switched Reluctance Motor, Torque Ripple, Hysteresis Current Control ****

\section{INTRODUCTION}

The Switched Reluctance Motor (SRM) drives have become popular in recent times because such as simple structure, no winding on rotor, adaptability to explosive environments. An accurate dynamic model is required to predict the performance of the drive. The phase inductance or phase flux-linkage is a non-linear function of position of rotor and stator current. If the effect of magnetic saturation is neglected, inductance is a linear function of rotor position[1,2].

At lower speeds, the motor back-EMF is small compared to the supply voltage and the current flowing through the stator winding can be regulated by Hysteresis Current Control. The Hysteresis Current Controller maintains the current between an upper and a lower limit in the set hysteresis band. So, Hysteresis Current Control method is applied to low and medium speeds. Due to double saliency structure, the torque ripples are high in SR motors compared to sinusoidal machines.Torque ripples can be minimized by changing the magnetic design and also by varying turn-on and turn-off angles of the converter [3].

Developed torque in SRM depends on the turn-off angle of the converter and may lead to unstable or stable operation. The turn-off angle is variable and depends on the speed of the motor. Hamid Ehsan Akhter et al. have analyzed the performance of SRM drive with different fixed turn-off angles and suggested an optimum value that gives a good performance. During this study turn-on angle is fixed [4].

Hamid Ehsan Akhter et al. have also presented a method of minimizing the torque ripple by varying both turn-on angle and turn-off angles. Finally, an optimum pair of switching angles for which torque ripple is minimum has been obtained [5]. The torque produced by any particular phase of the SRM is depends on the exciting current and period during which the current is carried out by that phase current.
The conduction period of any particular phase is termed as Dwell angle when it is specified in terms of rotor angular position. G.Bhuvaneshwari et al. have studied the drive performance in terms of torque ripple for various Dwell angles. From the analysis, a methodology has been devised to deduce an appropriate value of dwell angle for minimizing the torque ripple [6].

This paper analyses the performance for different turn on and turn off angles of the converter to find out an optimal pair through simulation studies.

\section{SIMULATION AND ANALYSIS OF SRM HYSTERESIS CURRENT CONTROL WITH}

The complete Non-linear model of SRM with Hysteresis Current Control is shown in Figure 1 (a). The model has electrical and mechanical systems, position sensor, Asymmetric converter, PI controller and Hysteresis Current Control blocks. Figure 1 (b) shows the internal model for one phase.

The performance of the Hysteresis Current Control is analyzed for a Fan type load of $8 \mathrm{Nm}$ and at a reference speed of $800 \mathrm{rpm}$. The actual speed is compared with the reference speed and the speed error is fed to a PI controller. The maximum current in the PI controller is set at $13 \mathrm{~A}$. The controller constants $\mathrm{K}_{\mathrm{p}}$ and $\mathrm{K}_{\mathrm{i}}$ are determined by trial and error method and they are found to be 20 and 0.1 respectively. The current hysteresis band is set at $1 \mathrm{~A}$. The simulation is performed for different values of $\theta_{\text {on }}$ and $\theta_{\text {off }}$ to find out a pair for which the torque ripple is minimum $[4,5$, 6]. Table 1 shows the variation of the torque ripple and settling time of the speed for different combinations of $\theta_{\text {on }}$ and $\theta_{\text {off. }}$ It is observed that at $\theta_{\text {on }}=0^{\circ} \& \theta_{\text {off }}=29^{\circ}$ the torque ripple is minimum and at $\theta_{\text {on }}=2^{0} \& \theta_{\text {off }}=29^{\circ}$ the torque ripple is maximum. 
The simulation results of the Hysteresis Current Controlled SRM drive with Fan type load for $\theta_{\text {on }}=0^{\circ}$ and $\theta_{\text {off }}=29^{\circ}$ are shown in Figure 2. Instantaneous phase currents of the four phases during the acceleration period are shown in Figure 2 (a). It is observed that the current in each phase is maintained at set value of $13 \mathrm{~A}$ by maintaining a set hysteresis band of $1 \mathrm{~A}$. Figure 2 (b) shows the instantaneous currents in the steady state. The average value of current in each phase is $5.28 \mathrm{~A}$ and the peak value of current is 13.52 A. The instantaneous torques in the steady-state is shown in the Figure 2 (c). It is observed that there is small negative torques in each phase but the total torque developed by the SRM is positive and equal to load torque. Figure 2 (d) shows the total torque developed by the motor over the entire simulation time. The total torque in the steady state is shown in Figure 2 (e). The maximum and minimum values of the torque are $8.64 \mathrm{Nm}$ and $7.56 \mathrm{Nm}$ respectively and the calculated torque ripple is $13.87 \%$. The load torque is shown in Figure 2 (f). The speed response is shown in Figure $2(\mathrm{~g})$ and settling time of speed is $0.101 \mathrm{sec}$. The switching frequency of the switching device is not constant in Hysteresis Current Control. The switching frequency varies between $980 \mathrm{~Hz}$ and $12.24 \mathrm{kHz}$.

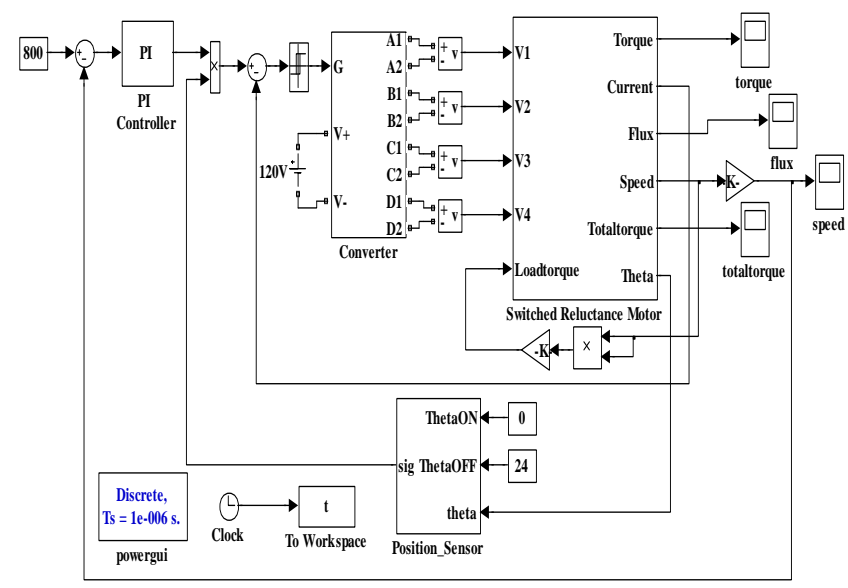

(a)

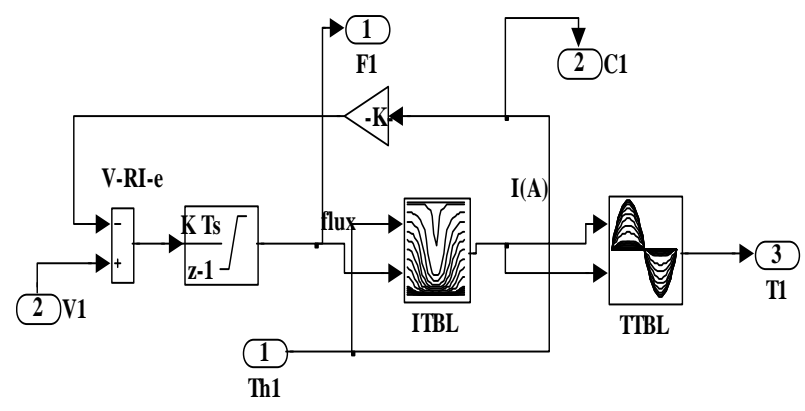

(b)

Fig -1: (a) Simulation diagram of SRM drive with Hysteresis Current Control (b) Internal model of one phase
Table-1: Variation of torque ripple with angles for Hysteresis Current Control with Fan type load

\begin{tabular}{|l|l|l|l|l|}
\hline S.No. & $\begin{array}{l}\boldsymbol{\theta}_{\text {on }} \\
(\text { Deg. })\end{array}$ & $\begin{array}{l}\boldsymbol{\theta}_{\text {off }} \\
(\text { Deg. })\end{array}$ & $\begin{array}{l}\text { \% Torque } \\
\text { ripple }\end{array}$ & $\begin{array}{l}\text { Settling time } \\
(\mathrm{Sec})\end{array}$ \\
\hline 1 & $0^{0}$ & $23^{0}$ & 19.37 & 0.118 \\
\hline 2 & $0^{0}$ & $24^{0}$ & 18.87 & 0.113 \\
\hline 3 & $0^{0}$ & $25^{0}$ & 18.75 & 0.108 \\
\hline 4 & $0^{0}$ & $26^{0}$ & 17.25 & 0.105 \\
\hline 5 & $0^{0}$ & $27^{0}$ & 16.50 & 0.102 \\
\hline 6 & $0^{0}$ & $28^{0}$ & 16.62 & 0.102 \\
\hline $\mathbf{7}$ & $\mathbf{0}^{\mathbf{0}}$ & $\mathbf{2 9}^{\mathbf{0}}$ & $\mathbf{1 3 . 8 7}$ & $\mathbf{0 . 1 0 1}$ \\
\hline 8 & $1^{0}$ & $29^{0}$ & 18.62 & 0.106 \\
\hline 9 & $1^{0}$ & $28^{0}$ & 18.75 & 0.106 \\
\hline 10 & $1^{0}$ & $27^{0}$ & 17.12 & 0.106 \\
\hline 11 & $1^{0}$ & $26^{0}$ & 17.87 & 0.109 \\
\hline 12 & $1^{0}$ & $25^{0}$ & 18.87 & 0.111 \\
\hline 13 & $1^{0}$ & $24^{0}$ & 19.00 & 0.175 \\
\hline $\mathbf{1 4}$ & $\mathbf{2}^{\mathbf{0}}$ & $\mathbf{2 9}^{\mathbf{0}}$ & $\mathbf{2 8 . 0 0}$ & $\mathbf{0 . 1 1 3}$ \\
\hline 15 & $2^{0}$ & $28^{0}$ & 24.50 & 0.110 \\
\hline 16 & $2^{0}$ & $27^{0}$ & 20.37 & 0.113 \\
\hline 17 & $2^{0}$ & $26^{0}$ & 17.12 & 0.115 \\
\hline
\end{tabular}

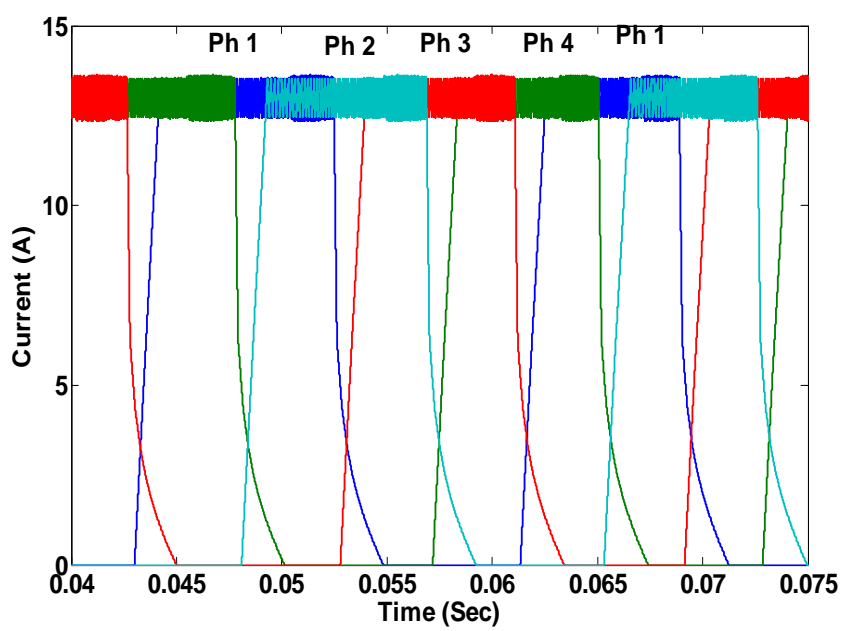

(a)

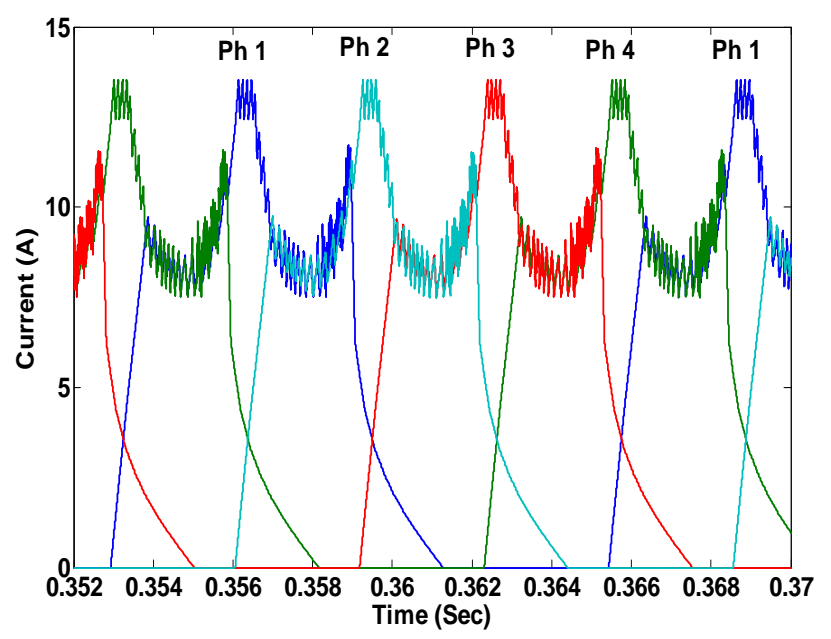

(b) 


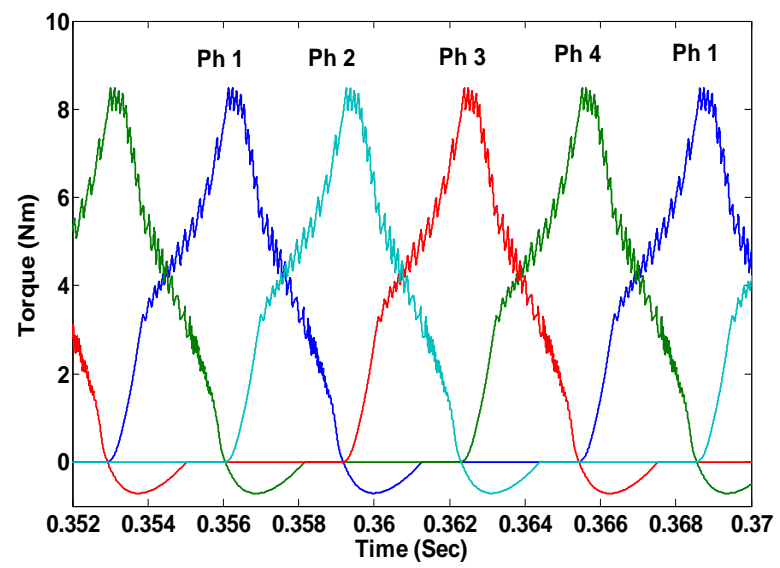

(c)

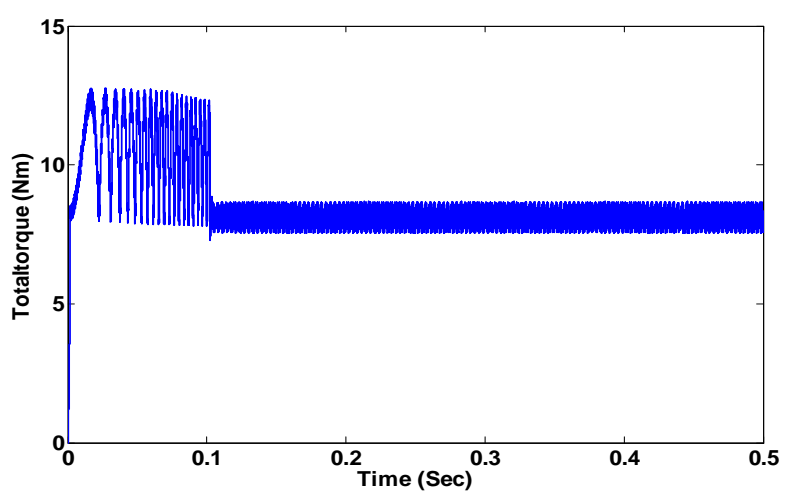

(d)

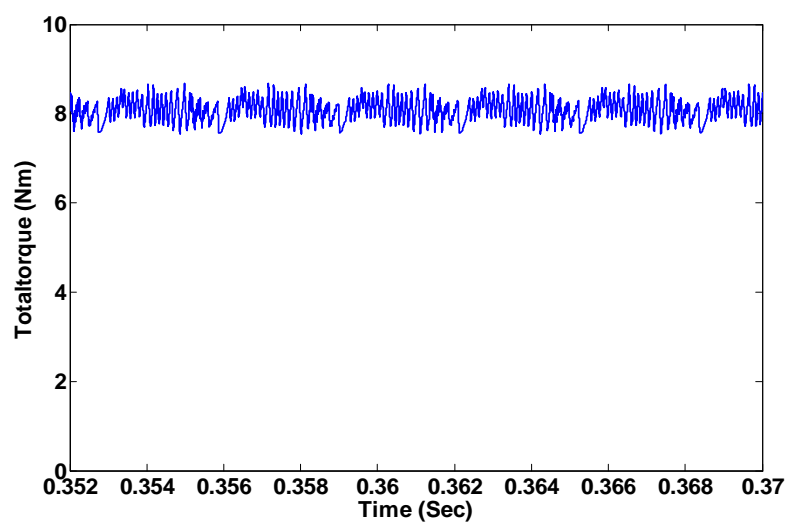

(e)

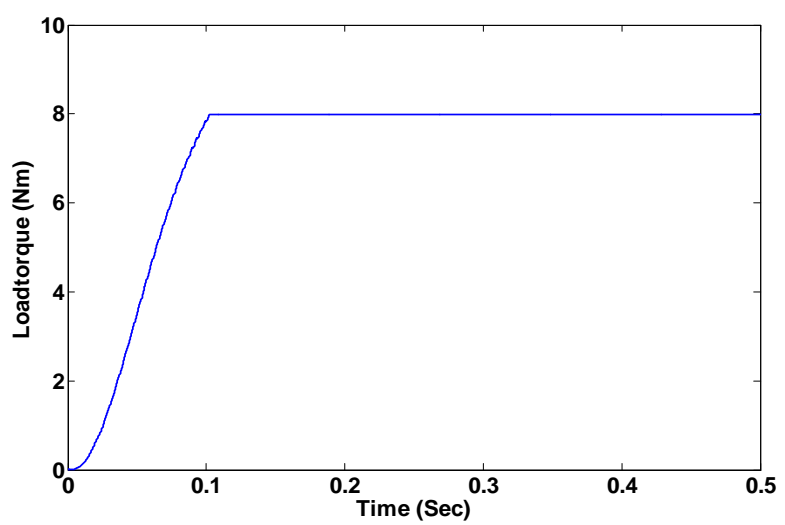

(f)

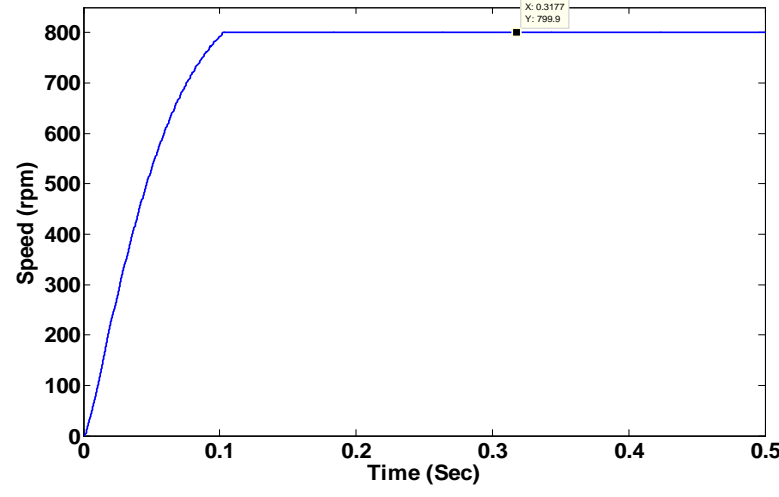

(g)

Fig -2 Hysteresis Current Control with Fan type load for $\theta_{\text {on }}$ $=0^{0} \& \theta_{\text {off }}=29^{\circ}$ (a) Phase currents during acceleration (b) Phase currents in the steady state (c) Phase torques (d) Total torque (e) Total torque in the steady state (f) Load torque (g) Speed

\section{CONCLUSIONS}

The SRM is simulated with Hysteresis Current Controller for Fan load. The analysis has been conducted for different combinations of turn-off and turn-on angles to find out a pair for which the ripple is minimum. It has been observed that with Hysteresis Current Control the value of maximum torque and torque ripple is high for Fan type load at $\theta_{\text {on }}=2^{0}$ $\& \theta_{\text {off }}=29^{\circ}$.

\section{REFERENCES}

[1]. T.J.E.Miller, "Switched Reluctance Motors and their Control," Magna Physics Publishing \& Oxford University Press, 1993.

[2]. T.J.E.Miller, "Electronic Control of Switched Reluctance Machines," Newnes Press, 2001.

[3]. Iqbal Husain, "Minimization of Torque Ripple in SRM Drives," IEEE Transactions on Industrial Electronics, Vol. 49, No. 1, February 2002.

[4]. Hamid Ehsan Akhter, Virendra K.Sharma, A.Chandra and Kamal Al-Haddad, "Performance Simulation of Switched Reluctance Motor Drive System Operating with Fixed Angle Control Scheme," in the proceedings of Electrimacs, 2002.

[5]. Hamid Eshan Akhter, K.Virendra Sharma, Ambrish Chandra and Kamal Al-Haddad, "Modeling Simulation and Performance Analysis of Switched Reluctance Motor Operating with Optimum value of Fixed Turn-On and Turn-Off Switching Angles" in proceedings of IEEE 34th Annual Power Electronics Specialist Conference, Vol. 1, 2003, pp.397-402.

[6]. G.Bhuvaneshwari, P.Srinivas Rao, and S.S.Murthy, "Impact of Dwell Angle on the Electromagnetic Torque Ripples of the Switched Reluctance Motor," Defence Science Journal, Vol. 58, No.3, May 2008, pp.363- 371 . 